\title{
An evaluation of eating attitudes in patients with migraine and tension type headache
}

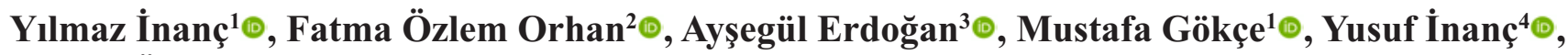 \\ Erdem Özyurt ${ }^{5} \odot$
}

${ }^{1}$ Department of Neurology, Kahramanmaraş Sütçü Imam University School of Medicine, Kahramanmaraş, Turkey ${ }^{2}$ Department of Psychiatry, Kahramanmaraş Sütçü Imam University School of Medicine, Kahramanmaraş, Turkey

${ }^{3}$ Department of Public Health, Kahramanmaraş Sütçü Imam University School of Medicine, Kahramanmaraş, Turkey

${ }^{4}$ Department of Neurology, Gaziantep University School of Medicine, Gaziantep, Turkey

${ }^{5}$ Department of Neurology, Mardin State Hospital, Mardin, Turkey

DOI: $10.18621 /$ eurj.396989

\begin{abstract}
Objective: The aim of the study was to examine eating attitudes in patients with migraine and tension type headache.

Methods: The study included 89 patients diagnosed with migraine according to the International Headache Society (IHS) 2004 criteria, 87 patients with tension type headache and 89 healthy volunteers matched in terms of age, gender and education level. A detailed neurological examination was made of all the participants and the Eating Attitudes Test (EAT), the Beck Anxiety Inventory (BAI) and the Beck Depression Inventory (BDI) were applied.

Results: In the comparisons of the EAT points, 23 of the tension type headache group and 18 of the migraine group were in the EAT $\geq 30$ group, which was a statistically significantly higher rate compared to the control group ( $p=0.099$ ). The mean BDI points and the mean BAI points of both the migraine and the tension type headache groups were statistically significantly higher than those of the control group $(p=0.001$ and $p=0.002$, respectively).

Conclusions: The results showed impairment in the eating attitudes of patients with migraine and tension type headache compared to the control group. When it is considered that some foodstuffs trigger headaches, eating disorders or impaired attitudes to eating become important.
\end{abstract}

Keywords: migraine, tension type headache, eating attitude

Received: February 20, 2018; Accepted: July 25, 2018; Published Online: August 16, 2018

H eadache is encountered extremely often in neurology practice. This is a significant health problem that causes a loss of workforce leading to personal, societal and economic losses and has a negative effect on an individual's quality of life [1]. The World Health Organisation (WHO) counts migraine as one of the diseases that creates the most limitation [2]. Migraine and tension type headache (TTH) are the two most often seen clinical tables in headaches [3, 4]. Eating disorders (eg, anorexia nervosa, bulimia nervosa) have both physical and psychological components and are seen particularly in young females.

Address for correspondence: Yılmaz İnanç, MD., Assistant Professor, Kahramanmaraş Sütçü Imam University School of Medicine, Department of Neurology, Kahramanmaraş, Turkey 
Psychological and biological factors have been held responsible in the pathophysiology of eating disorders. Psychological factors include states such as depression, anxiety, obsessive symptoms and low self-esteem, while biological factors are serotonin, norepinephrine and dopamine metabolism disorders. However, the pathophysiology has not been fully clarified $[5,6]$. The common pathways of eating disorders and migraine are that they are both seen more often in females, there is a high rate of psychiatric comorbidity and there are changes in serotonin metabolism in both diseases.

The aim of this study was to examine the attitudes to eating of patients with migraine and tension type headache.

\section{METHODS}

The study included 89 patients who presented with the complaint of headache at the Neurology Polyclinic of Kahramanmaraș Sütçü Imam University Medical Faculty Hospital between February and August 2016 and were diagnosed with migraine by a neurology specialist according to the International Headache Society (IHS) 2004 criteria, 87 patients with tension type headache and 89 healthy volunteers matched in terms of age, gender and education level. Approval for the study was granted by the Ethics Committee of Kahramanmaraş Sütçü Imam University. Informed consent was obtained from all the study participants.

Inclusion criteria were that participation was voluntary, the patients were literate, aged 18-45 years, not taking any regular medication, and that those in the migraine group had no disease other than migraine and those in the control group were healthy. The sociodemographic data of the participants were recorded. Height and weight were measured and the Body Mass Index (BMI) was calculated. According to the BMI values, 3 groups were formed of $<18.49$ low BMI, 18.5-24.9 normal BMI and $\geq 25$ high BMI. In the migraine group, the duration of the disease, duration of attacks and frequency of attacks were evaluated. A detailed neurological examination was made of all the participants. The Eating Attitudes Test (EAT), the Beck Anxiety Inventory (BAI) and the Beck Depression Inventory (BDI) were applied. The patients were grouped according to the EAT points as
EAT $<30$ and EAT $\geq 30$ and according to the BDI points as $\mathrm{BDI}<17$ and $\mathrm{BDI} \geq 17$.

\section{The Eating Attitudes Test (EAT)}

The Eating Attitudes Test used in this study is a self-reporting scale comprising 40 items with 6 Likerttype responses. It was developed by Garner and Garfinkel in 1979 for screening purposes to objectively measure symptoms of anorexia nervosa, and can be applied to individuals over the age of 11 years. Just as it measures the attitudes and behaviour towards food of anorexia nervosa patients it can also identifty potential disorders in eating behaviour of normal individuals. The validity and reliability studies of this scale for use in Turkey were conducted by Savasir and Erol. Points over the accepted cutoff of 30 are accepted as an eating disorder [7, 8].

\section{Beck Depression Inventory (BDI)}

This is a self-evaluation form of 21 items scored from 0-3 as Likert-type responses. The scale was developed by Beck and aims to measure the severity of symptoms related to depression in cognitive, emotional, motivational and physical dimensions and takes the mental state of the previous week into consideration. The total points indicate the severity of depression, with a maximum of 63 points and a cutoff of 17 points, as defined by Hisli in validity and reliability studies for Turkey $[9,10]$.

\section{Beck Anxiety Inventory (BAI)}

This self-reporting scale measures the extent of anxiety symptoms experienced by the individual. The scale consists of 21 items scored from $0-3$ and the total points indicate the severity of anxiety experienced. Validity and reliability studies for Turkey were conducted by Ulusoy et al and 17 points are accepted as the cutoff point $[11,12]$.

\section{Statistical analysis}

Analyses of the data obtained were made using SPSS soft ware (Statistical Package for the Social Sciences). Descriptive statistics were reported as mean \pm standard deviation, number and percentage. The Chi-square test was applied to categorical data, and in the comparison of mean points, the Kruskal Wallis test was used. A value of $p<0.05$ was accepted as statistically significant. 


\section{RESULTS}

A total of 265 participants were evaluated in the study, as 89 in the migraine group, 87 in the TTH group and 89 in the control group. The mean age was mean $34.21 \pm 9.07$ years in the migraine group, 35.79 \pm 9.05 years in the TTH group and $32.82 \pm 9.28$ years in the control group. No statistically significant difference was determined between the groups in respect of age or gender $(p>0.05)$. The sociodemographic data of the migraine, TTH and the control groups and the clinical data of the migraine and TTH groups are shown in Table 1.

In the migraine group, the duration of the complaint of headache was $5.09 \pm 3.14$ years, the frequency of attacks was $4.16 \pm 1.87$ per month and the mean duration of attacks was $19.65 \pm 15.77$ hours. In men, the duration of complaint of headache was $5.62 \pm 3.11$ years, the attack frequency was $2.87 \pm 1.45$ attacks/month and the duration of attack was $13.62 \pm$ 15.24 hours. In women, the duration of complaint of headache was $5.11 \pm 3,18$ years, the attack frequency was $4.39 \pm 1.87$ attacks/ month and the duration of attack was $20.87 \pm 14.46$ hours.

In the comparisons of the EAT points, 23 of the TTH group and 18 of the migraine group were in the EAT $\geq 30$ group, which was a statistically significantly higher rate compared to the control group $(p=0.099)$. The mean BDI points and the mean BAI points of both the migraine and the TTH groups were statistically significantly higher than those of the control group ( $p$ $=0.001$ and $p=0.002$, respectively) (Table 2 ).

When the groups were evaluated in respect of those with $\mathrm{BMI} \geq 25,59$ of the migraine group, 55 of the TTH group and 44 of the control group were determined with high BMI. The number of patients in the migraine and TTH groups with high BMI was determined to be statistically significantly higher than the control group ( $p=0.048)$ (Table 2).

The mean EAT points, mean BDI points, mean BAI points and mean BMI values of the migraine group and the TTH group were determined to be

Table 1. Sociodemographic characteristics of the migraine, TTH and control groups

\begin{tabular}{|c|c|c|c|}
\hline & $\begin{array}{l}\text { Migraine } \\
(n=89) \\
\end{array}$ & $\begin{array}{c}\text { Tension type } \\
\text { headache } \\
(n=87)\end{array}$ & $\begin{array}{l}\text { Control } \\
(\mathrm{n}=\mathbf{8 9}) \\
\end{array}$ \\
\hline Age (years) & $34.21 \pm 9.07$ & $35.79 \pm 9.05$ & $32.82 \pm 9.28$ \\
\hline \multicolumn{4}{|l|}{ Gender } \\
\hline Female & $81(91.0 \%)$ & $73(83.9 \%)$ & $78(87.6 \%)$ \\
\hline Male & $8(9.0 \%)$ & $14(16.1 \%)$ & $11(12.4 \%)$ \\
\hline \multicolumn{4}{|l|}{ Marital status } \\
\hline Married & $75(84.3 \%)$ & $57(82.6 \%)$ & $55(61.8 \%)$ \\
\hline Single /widowed/divorced & $14(15.7 \%)$ & $12(17.4 \%)$ & $34(38.2 \%)$ \\
\hline \multicolumn{4}{|l|}{ Level of education } \\
\hline Primary school or lower & $48(53.9 \%)$ & $55(63.2 \%)$ & $15(19.1 \%)$ \\
\hline Middle school-High school & $28(31.5 \%)$ & $19(21.8 \%)$ & $23(25.8 \%)$ \\
\hline Further education & $13(14.6 \%)$ & $13(14.9 \%)$ & $49(55.1 \%)$ \\
\hline \multicolumn{4}{|l|}{ Place of residence } \\
\hline City centre & $60(69.0 \%)$ & $57(67.1 \%)$ & $74(83.1 \%)$ \\
\hline Regional town/village & $27(31.0 \%)$ & $28(32.9 \%)$ & $15(16.9 \%)$ \\
\hline \multicolumn{4}{|l|}{ Employment status } \\
\hline Employed & $29(32.6 \%)$ & $27(31.0 \%)$ & $63(70.8 \%)$ \\
\hline Unemployed & $60(67.4 \%)$ & $60(69.0 \%)$ & $29(29.2 \%)$ \\
\hline \multicolumn{4}{|l|}{ Economic status } \\
\hline Poor & $12(13.6 \%)$ & $10(11.6 \%)$ & $11(12.4 \%)$ \\
\hline Average & $71(80.7 \%)$ & $73(84.9 \%)$ & $72(80.9 \%)$ \\
\hline Good & $5(5.7 \%)$ & $3(3.5 \%)$ & $6(6.7 \%)$ \\
\hline
\end{tabular}

Data are shown as mean \pm standard deviation or number $(\%)$. 
Table 2. Comparisons of the groups

\begin{tabular}{lcccc}
\hline & Migraine & $\begin{array}{c}\text { Tension type } \\
\text { headache } \\
(\mathbf{n}=\mathbf{8 7})\end{array}$ & Control & $\boldsymbol{p}^{*}$ value \\
& $(\mathbf{n}=\mathbf{8 9})$ & $23(26.4 \%)$ & $12(13.5 \%)$ & 0.099 \\
$\mathrm{EAT} \geq 30$ & $18(20.2 \%)$ & $29(33.3 \%)$ & $10(11.2 \%)$ & $\mathbf{0 . 0 0 1}$ \\
$\mathrm{BDI} \geq 17$ & $34(38.2 \%)$ & $38(43.7 \%)$ & $21(23.6 \%)$ & $\mathbf{0 . 0 0 2}$ \\
$\mathrm{BAI} \geq 17$ & $42(47.2 \%)$ & $55(63.2 \%)$ & $44(49.4 \%)$ & $\mathbf{0 . 0 4 8}$ \\
$\mathrm{BMI} \geq 25$ & $59(66.3 \%)$ & &
\end{tabular}

Data are shown as mean \pm standard deviation or number $(\%)$. EAT $=$ Eating Attitudes Test, BDI $=$ Beck Depression Inventory, BAI = Beck Anxiety Inventory, BMI = Body Mass Index, *Kruskal Wallis test

Table 3. Comparisons of the groups

\begin{tabular}{lcccc}
\hline Tests & Migraine & $\begin{array}{c}\text { Tension type } \\
\text { headache } \\
(\mathbf{n}=\mathbf{8 7})\end{array}$ & $\begin{array}{c}\text { Control } \\
(\mathbf{n = 8 9 )}\end{array}$ & $\boldsymbol{p}^{*}$ value \\
\hline EAT & $\mathbf{( n = 8 9 )}$ & $24.61 \pm 17.21$ & $16.21 \pm 12.27$ & $\mathbf{0 . 0 0 1}$ \\
BDI & $21.73 \pm 10.56$ & $13.45 \pm 8.28$ & $8.85 \pm 8.58$ & $\mathbf{0 . 0 0 1}$ \\
BAI & $15.51 \pm 10.18$ & $17.08 \pm 12.36$ & $10.10 \pm 7.61$ & $\mathbf{0 . 0 0 1}$ \\
BM & $16.99 \pm 12.61$ & $27.74 \pm 4.82$ & $25.48 \pm 4.05$ & $\mathbf{0 . 0 1 4}$ \\
\hline
\end{tabular}

Data are shown as mean \pm standard deviation. EAT $=$ Eating Attitudes Test, BDI $=$ Beck Depression Inventory, BAI = Beck Anxiety Inventory, BMI = Body Mass Index, *Kruskal Wallis test

statistically significantly higher than those of the control group (Table 3). The highest mean EAT points and mean BDI points were determined in the migraine group. The highest mean BAI points were determined in the TTH group. The mean BMI values of the migraine and TTH groups were close to each other and were higher than those of the control group (Table 3 ).

\section{DISCUSSION}

Headache should be addressed not only in limiting the individual's social activities and work life, but also in terms of the multidimensional burden brought about by the collection of health expenditures, such as increasing drug consumption and many hospital applications and examining behaviors. Headache is the "primary headache" when an organic cause can not be determined; secondary headache "if it is associated with an organic pathology such as trauma, infection, or tumor. Approximately $90 \%$ of the headache is the primary headache, migraine and tension type headache are the two most common types of headache.
Migraine, and tension type headache, which is the second most common type of primary headaches, are a neurological disease characterised by moderate or severe recurrent attacks of headache accompanied by various combinations of neurological, gastrointestinal and autonomous symptoms. TTH can last from 30 minutes to 7 days and is a headache type that can become chronic with continuous pain. According to epidemiological studies in Turkey, the prevalence of TTH is $31.7 \%$ and migraine has been reported as $16.4 \%[13,14]$.

Although primary headache is considered as a neurological pathology, it is frequently observed in the literature with psychiatric disorders such as anxiety and depression attention. Migraine is related to several psychiatric disorders such as major depression, bipolar disorder and anxiety disorder. In a study conducted in the United States of America, depressive disorder is three times more common in migraineurs than in the general population, and this rate is even greater in patients with GTBA or overuse [15]. Studies have revealed that there could be a relationship between migraine and eating disorders and it has been 
suggested that there is a common biological predisposition [16, 17].

In the current study, an impaired eating attitude was determined in $34 \%$ of the migraine patients and in $43.4 \%$ of the TTH patients. These findings were determined to be higher than those of the control group but no statistically significant difference was determined between the groups. However, the mean EAT points of the migraine and TTH groups were found to be statistically significantly higher than those of the control group. To the best of our knowledge, this is the first study to have evaluated eating attitudes and eating disorders in patients with migraine and TTH. Demirci et al. [18] reported that the EAT points were significantly higher in a group of 59 migraine patients compared to a control group, and in the evaluation according to the EAT cutoff points, eating disorders were determined more in the migraine patients.

In a study of 34 migraine patients by Brewerton and George [19], 88\% were determined with dieting behaviour, $59 \%$ with overeating and $26 \%$ with selfinduced vomiting. In both studies, it was suggested that serotonin dysfunction could be a common pathophysiology of both diseases. Serotonin is a neuropeptide that controls energy intake by providing a sense of satiety. Although serotonin shows transient elevations during migraine attacks, migraines are low in the interictal period. This may lead to an increase in eating impulse and development of obesity in migraineurs [20].

When the groups in the current study were evaluated in respect of those with $\mathrm{BMI} \geq 25$, the number of those in the migraine and TTH groups with $\mathrm{BMI} \geq 25$ was found to be statistically significantly higher than those in the control group $(p=0.048)$. In patients with chronic migraine, impaired insulin resistance, hypertension, diabetes, high cholesterol and obesity have been reported to be widely seen [21, 22].

In recent years, it has been thought that some orexigenic and anorexigenic peptides expressed from the hypothalamus related to appetite metabolism could have a role in the pathogenesis of migraine and obesity. Just as increased appetite, hypothalamic stimulants such as mood and sleep problems and postdromal symptoms seen in migraine have been associated with this state, it has also been reported that it could cause hyperphagia of the hypothalamus membrane and an increase in body weight in migraine [23]. The induction of migraine trigeminal ganglion nociceptors causes the release of proinflammatory substances such as CGRP and substance P. CGRP levels are also high in obese patients and are increasing with fat intake. Substance P is present in adipocytes and leads to fat deposition and proinflammatory environment [24]. It has been shown that there could be psychological factors such as accompanying anxiety, depression, obsessivecompulsive disorder and body dysmorphia disorders in the pathophysiology of eating disorders seen in migraine patients $[25,26]$.

In the multicentre HADAS study (headache and anxiety depressive disorder comorbidity), a frequent combination was shown of TTH and psychiatric disorders. In the current study, TTH was seen to be accompanied by psychopathologies, primarily depression, followed by anxiety, panic disorder and obsessive compulsive disorder. Depressive disorder has been reported in $68.3 \%$ of TTH patients and anxiety disorder in $19.3 \%$ [27]. In a study by Mustelin et al. [28], it was reported that eating disorders in migraine patients could be explained by concomitant major depression. Büyükgöze-Kavas [29] reported a significant relationship between general eating attitudes and depression symptoms. In the current study, both the BDI and BAI points were determined to be statistically significantly higher in both the migraine and TTH patients compared to the control group ( $p=0.001$ and $p=0.002$, respectively).

\section{Limitations}

Limitations of the current study were that the sample size was small, it was a single centre study and the scales used do not have diagnostic properties.

\section{CONCLUSION}

The results of the current study showed that the risk of eating disorders in patients with migraine and TTH is higher than that of the general population. In the follow-up and treatment of migraine patients, when it is considered that some foodstuffs can trigger headache, the presence of eating disorders or a poor attitude to eating becomes more important. This type 
of screening in respect of eating disorders should be applied to this group of patients so that early diagnosis would allow the possibility of the necessary treatment.

\section{Conflict of interest}

The authors disclosed no conflict of interest during the preparation or publication of this manuscript.

\section{Financing}

The authors disclosed that they did not receive any grant during conduction or writing of this study.

\section{REFERENCES}

[1] Karlı N, Zarifoğlu M, Erteș M, Saip S, Öztürk V, Neyal M, et al. Economic impact of primary headaches in Turkey: a university hospital based study: part II. J Headache Pain 2006;7:75-82.

[2] Bradley WG, Daroff BR, Fenichel GM, Jankovic J, Ed: Tan E, Özdemir SE. Neurology in Clinical Practice. 5. Bask1, Ankara: Kalkan Matbaacilık, 2008; 134-210, 2011-2059.

[3] Ropper HA, Samuels MA, Ed: Emre M. Adams and Victor's Principles of Neurology, 9th ed. Ankara: Detail printing press. 2011;162-188.

[4] Jensen RH. Tension-type headache--The normal and most prevalent headache. Headache 2018;58:339-45.

[5] Avraham Y, Hao S, Mendelson S, Berry EM. Tyrosine improves appetite, cognition, and exercise tolerance in activity anorexia. Med Sci Sports Exerc 2001;33:2104-10.

[6] D’Andrea G, Ostuzzi R, Bolner A, Colavito D, Leon A. Is migraine a risk factor for the occurrence of eating disorders? Prevalence and biochemical evidences. Neurol Sci 2012;33:7176.

[7] Garner DM, Garfinkel PE. The Eating Attitudes Test: an index of the symptoms of anorexia nervosa. Psychol Med 1979;9:2739.

[8] Savaşır I, Erol N. Eating Attitude Test: Anorexia Nervosa Symptom Index. Psychol J 1989;7:19-25.

[9] Beck AT, Ward CH, Mendelson M, Mock J, Erbaugh J. An inventory for measuring depression. Arch Gen Psychiatry 1961;4:561-71.

[10] Hisli N. The validity and reliability of the Beck Depression Inventory for university students. J Psychol 1989;7:3-13.

[11] Beck AT, Epstein N, Brown G, Steer RA. An inventory for measuring clinical anxiety: Psychometric properties. J Consult Clin Psychol 1988;56:893-7.

[12] Ulusoy M, Şahin N, Erkmen H. Turkish version of The Beck Anxiety Inventory: Psychometric properties. J Cogn Psychother 1998;12:28-35.
[13] Baykan B. Headaches. Neurology. Second edition, Istanbul: Nobel Medical Bookstore, 2011;373-93.

[14] Carbaat PA, Couturier EG. [Headache: classification and diagnosis]. Ned Tijdschr Tandheelkd 2016;123:539-44. [Article in Dutch]

[15] Martin PR, Forsyth MR, Reece J. Cognitive-behavioral therapy versus temporal pulse amplitude biofeedback training for recurrent headache. Behav Therapy 2007;38:350-63.

[16] D’Andrea G, Ostuzzi R, Francesconi F, Musco F, Bolner A, D'Onofrio F, et al. Migraine prevalence in eating disorders and pathophysiological correlations. Neurol Sci 2009;30:55-9.

[17] D’Andrea G, Ostuzzi R, Bolner A, Francesconi F, Musco F, d'Onofrio F, et al. Study of tyrosine metabolism in eating disorders. Possible correlation with migraine. Neurol Sci 2008;29:88-92.

[18] Demirci K, Demirci S, Akpinar A, Demirdaş A, Atay İM. Evaluation of eating attitude in patients with migraine. Noro Psikiyatr Ars 2015;52:367-70.

[19] Brewerton TD, George MS. Is migraine related to the eating disorders? Int J Eat Disord 1993;14:75-79.

[20] Alstadhaug KB. Migraine and the hypothalamus. Cephalalgia 2009;29:809-17.

[21] Fava A, Pirritano D, Consoli D, Plastino M, Casalinuovo F, Cristofaro S, et al. Chronic migraine in women is associated with insulin resistance: A crosssectionalstudy. Eur J Neurol 2014;21:267-72.

[22] Bigal EM, Lipton BR. Obesity is a risk factor for transformed migraine but not chronic tension-type headache. Neurology 2006;67:252-7.

[23] Peterlin BL, Rosso AL, Williams MA, Rosenberg JR, Haythornthwaite JA, Merikangas KR, et al. Episodic migraine and obesity and the influence of age, race, and sex. Neurology 2013;81:1314-21.

[24] Bond DS, Roth J, Nash JM, Wing RR. Migraine and obesity: epidemiology, possible mechanisms and the potential role of weight loss treatment. Obes Rev 2011;12:362-71.

[25] Seidel S, Karwautz A, Wagner G, Zormann A, Eder H, Huemer J, et al. Migraine in patients with eating disorders: a study usinga sister-pair comparison design. Headache 2011;51:220-5.

[26] Baskin SM, Smitherman TA. Migraine and psychiatric disorders: Comorbidities, mechanisms, and clinical applications. Neurol Sci 2009;30:S61-5.

[27] Beghi E, Allais G, Cortelli P, D'Amico D, De Simone R, d'Onofrio F, et al. Headache and anxiety-depressive disorder comorbidity: the HADAS study. Neurol Sci 2007;28 Suppl 2:S217-9.

[28] Mustelin L, Raevuori A, Kaprio J, Keski-Rahkonen A. Association between eating disorders and migraine may be explained by major depression. Int J Eat Disord 2014;47:884-7. [29] Büyükgöze-Kavas A. Eating attitudes and depression in a Turkish sample. Eur Eat Disord Rev 2007;15:305-10. 